\title{
WAKAF TUNAI (CASH WAQF) MENURUT PERSFEKTIF ULAMA DAN TINJAUAN MAQASHID SYARI'AH
}

\author{
Neni Hardiati \\ Program Studi magister Hukum Ekonomi Syariah, UIN Sunan Gunung Djati Bandung \\ Email: nenihardiati@gmail.com
}

\begin{abstract}
Abstrak
Wakaf adalah salah satu bentuk pelaksanaan ibadah yang merupakan contoh konkrit atas rasa keadilan. Dalam hal ini, Al-Qur"ean menyebutnya sebagai al-habs sinonim dari kata al-waqaf, yaitu harta benda milik seseorang yang diberikan untuk publik agar dapat dimanfaatkan selama barang itu tetap ada. Maka, esensi wakaf terletak pada wujud barangnya yang dalam ajaran Islam sebagai amal jariah yang bersifat terus-menerus. Seiring dengan kebutuhan dana untuk pengentasan kemiskinan yang sangat besar dan lokasinya tersebar di luar daerah para waqif inilah, maka muncul pemikiran untuk berwakaf dengan uang. Dengan kemudahan wakaf uang, maka masyarakat dapat dengan mudah membelanjakan uangnya untuk diwakafkan di jalan agama. Dasar wakaf dalam al-Qur'an dalam Surat Ali-Imran ayat 92, selain itu, dalam ayat Al-Qur'an surat Al-Hajj ayat 77. Ada pula hadist Rasulullah SAW yang lebih tegas dalam menggambarkan dianjurkannya ibadah wakaf, yaitu perintah Nabi kepada Umar untuk mewakafkan tanahnya yang ada di Khaibar. Mahzab Hanafi juga membolehkan wakaf tunai sebagai pengecualian, atas dasar istihsan bi al 'urfi (adat kebiasaan), karena sudah banyak dilakukan masyarakat. Menurut al Bakri, mahzab Syafi'i tidak membolehkan wakaf tunai, karena dinar dan dirham (uang) akan lenyap ketika dibayarkan sehingga tidak ada lagi wujudnya. Pendapat ulama mengenai obyek wakaf memperlihatkan bahwa syaratsyarat benda wakaf (harus benda, bermanfaat, tidak sekali pakai, tidak haram zatnya dan harus milik wakif secara sempurna). Wakaf tunai tidak didukung oleh hadis secara khusus, dan menggunakan ayat-ayat al-Qur'an dan hadis bersifat umum. Oleh karena itu, penentuan syarat-syarat obyek wakaf termasuk wilayah ijtihadi.
\end{abstract}

Kata Kunci: Wakaf Tunai, Hukum Wakaf, Maqasid Syariah

\begin{abstract}
Waqf is a form of worship which is a concrete example of a sense of justice. In this case, the Al-Qur'an calls it al-habs, a synonym of the word al-waqaf, namely property belonging to a person given to the public so that it can be used as long as the item remains. So, the essence of waqf lies in the form of the goods which in Islamic teachings are a continuous charity. In line with the enormous need for funds for poverty alleviation and the location is scattered outside the area of the waqifs, this has led to the idea of donating with money. With the convenience of cash waqf, people can easily spend their money to be waqf on the path of religion. The basis for waqf in the Koran is in Surah Ali-Imran verse 92, besides that, in the Qur'anic verse of Surat Al-Hajj verse 77. There is also the hadith of the Prophet Muhammad which is more explicit in describing the recommendation of waqf worship, namely the Prophet's command to Umar to donate his land in Khaibar. The Hanafi Mahzab also allows cash waqf as an exception, on the basis of istihsan bi al urfi (custom), because many people
\end{abstract}


have done it. According to al Bakri, the Syafi'I school does not allow cash waqf, because dinars and dirhams (money) will disappear when they are paid so that they no longer exist. The opinion of the scholars regarding the object of waqf shows that the conditions for waqf objects (must be objects, useful, not disposable, not haram in substance and must belong to waqf perfectly). Cash waqf is not supported by hadith specifically, and uses verses from the Koran and hadiths of a general nature. Therefore, the determination of the conditions for the waqf object is included in the ijtihadi area.

Keywords: Cash Waqf, Waqf Law, Maqasid Sharia.

\section{A. PENDAHULUAN}

Wakaf adalah salah sebuah kegiatan dalam agama Islam yang bernaung spiritual, pun ialah ibadah yang mementingkan setitik kebaikan demi keperluan universal yang berkesinambungan juga merupaakan suatu gerakan perniagaan, sementara donatur waqf mensedekahkan kekayannya untuk di alokasikan sepenuhnya unuk nadzir kelola. Sehingga benda yang di distribusikan oleh wakif, namun benda yang sudah di wakafkan tak dapat di tarik lagi, meskipun menghasilakan maslahat atas keuntungan dari pengelolaan benda tersebut. Kaidah waqf memiliki arti berhenti atau diam, juga barang yang di wakafkan. Di Indonesia sendiri memiliki arti benda yang di wakafkan oleh lembaga namun bendanya tidak boleh di jual (Munir, 2015).

Sebagai umat umat muslim kita sudah familiar melalui waqf tidak bergerak contohnya tempat ibadah dan sekolah. Kebiasaan masyarakat muslim sejak dahulu kala dalam berwakaf dengan objek wakaf tidak bergerak. Namun pekerjaan wakaf terdahulu ttidak efisien karena ini yang menikmati dan memanfaatkan benda wakaf tersebut adalah masyarkat yang tinggal di sekitar tempat objek wakaf tersebut berada. Sebab itu masyarakat diluar wakif tersebut tidak tersentuh. Sedangkan saat ini banyak rakyat penduduk kurang dalam finansial yang membutuhkan pertolongan menjalar lepas di seantero tanah air sebab itu memerlukan sumber permodalan baru yang tidak terkurung area dan durasi. Umat muslim memerlukan aset wakaf terkini yang mampu melaksanakan kemaslahatan oleh semua lapisan, seperti dibangun pusat belanja bahkan bisa untuk membantu siswa atau mahasiswa yang tidak beruntung untuk pendidikan (Arif, 2010).

Sejalan dengan keperluan modal dalam mengurangi masyarkat kurang beruntung dalam finasial yang terlampau luas denagn area menjalar di luar daerah para waqif, karena itu terbesit gagasan melaksankan cash waqf. Saat ini banyak sekali perbincangan mengenai wakaf tunai yang tidak hanya kepada pemikiran wakaf tanah atau benda bergerak lainnya saja, hal ini bukan hanya menyentuh sisi rohaniah saja namun dapat menyentuh sisi sosial 
kemanusiaan melalui menumbuhkan potensi kesejahtraan atau kemasalatan umum secara signifikan. Cash waqf dapat menjadi sebuah solusi berbagai permasalahan sosial bukan hanya keagamaan saja.

Menurut Antonio dalam (Isfandiar, 2008) cash wakaf memiliki 4 kegunaan, kesatu, uang ini dari segi kuantitas dapat bervariasi hal ini menjadi kabar gembira yang belum memiliki tanah atau bangunan dapat berwakaf dengan uang yang ia miliki. Kedua, melalui uang aset tanah yang tidak digunakan bisa dibangun atau di produktifkan melalui cash waqf ini, ketiga, uang wakaf dapat disalurkan untuk membantu institusi pendidikan yang tidak berkembang, keempat, dengan izin Allah swt akan mandiri dalam pendidiakan sehingga tidak menggantungkan diri kepada dana pendidikan dari pemerintah yang jumlahnya terbatas.

Berdasarkan pendapat beragam ahli ekonomi Islam, melakukan waakf melalui cash waqf ini mudah di laksankan dan efisen daripaa wakaf tidak bergerak. Hingga kini benda wakaf tidak bergerak seeprti tanah semakin langka jika pun ada harganya tinggi apalagi di wilyah kota besar. Sebab itu masyarkat Islam mendapati kesusahan ketika ingin berwakaf dengan tanah. Dengan kemudahan wakaf uang, maka masyarakat dapat dengan mudah membelanjakan uangnya untuk diwakafkan di jalan agama (Mahfudz, 2014).

Selain itu dengan wakaf uang, maka benda wakaf bisa dengan mudah digunakan, diinvestasikan atau dijalankan untuk usaha. Bagi pihak lembaga yang diberikan wakaf, dalam hal ini sekaligus pengelola (nadzir), juga lebih mudah untuk memanfaatkan benda wakaf. Karena menurut pengalaman, saat ini banyak tanah wakaf yang menganggur karena tidak subur dan tidak ditanami. Karena itu tanah tersebut dibiarkan begitu saja tanpa dimanfaatkan. Ini banyak terjadi di berbagai wilayah di tanah air. Kondisi seperti ini tentunya tidak sesuai dengan tujuan wakaf, yaitu mengekalkan benda wakaf untuk dimanfaatkan kaum muslimin. Sudah saatnya tanah wakaf diproduktifkan atau dicarikan jalan keluar yang lain untuk mengoptimalkan benda wakaf. Dengan wakaf uang ini, lembaga pengelola wakaf (nadzir) dapat dengan mudah menggunakan uang tersebut untuk dijadikan bisnis produktif. Kemudian hasil tersebut akan digunakan untuk kepentingan umat Islam secara luas (Karim, 2013).

Melalui tulisan wakaf tunai ini, kita akan mendapatkan kajian yang bermanfaat dan menarik, khususnya mengungkap potensi wakaf tunai di Indonesia yang sangat besar sebagai mayoritas penduduk muslim untuk membantu kesejahtraan sesasma dalam kegiatan keagamaan maupun sosial kemanusiaan sesuai dengan Hadist Riwayat Muslim: 


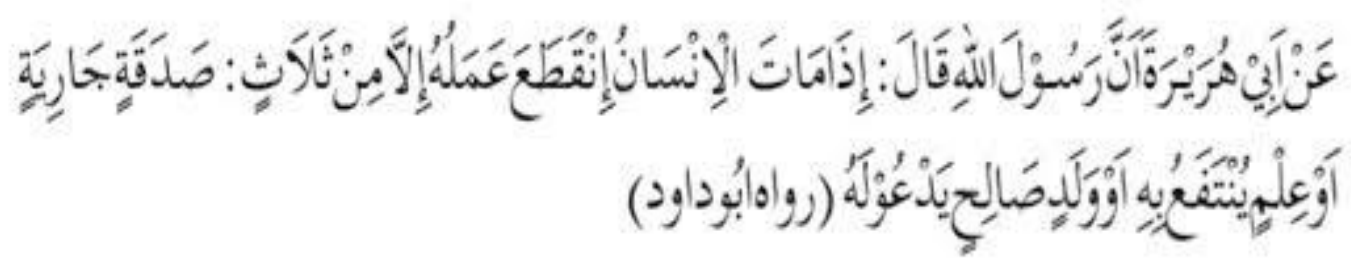

Dari Abu Hurairah radhiyallahu anhu, "sesungguhnya Rasulullah SAW bersabda: "Apabila anak adam (manusia) meninggal dunia, maka putuslah amalnya, kecuali tiga perkara: 1. shodaqah jariyah, 2. ilmu yang bermanfaat, 3. anak saleh yang mendoakan kedua orang tuanya" (H. R. Muslim No. 1631).

Dari hadist tersebut menyatakan bahwa ada 3 hal yang pahala amalnya tidak akan berhenti walaupun orangnya (wakif) sudah meninggal salah satunya "shadaqoh jariyah" yaitu bukan shadaqoh biasa, sebab shadaqoh lain (bukan wakaf) tidak menghasilkan pahala yang terus menerus (jariyah) karena benda yang di sedekahkan tidak kekal. Atas dasar tersebut maka wakaf dapat di kategorikan harta yang terus menerus memberikan pahala kepada wakif dari Allah SWT.

Aziz (2017), menyatakan bahwa umat Islam masih membiasakan diri dengan wakaf tanah yang manfaatnya hanya di peroleh oleh masyarakat sekitar tanah wakaf. Namun keberadaan wakaf tunai tersebut dapat menjangkau lapisan daerah untuk di salurkan dalam berbagai bidang pengentasan kemiskinan. Suryani \& Yunal (2016), menyatakan bahwa cash waqf merupakan terobosan baru dalam memberikan manfaat bagi kegiatan sosial yang sesuai dengan kaidah agama (maqashid alshariah). Artikel ini membahas tentang bagaimana hukum wakaf tunai menurut persfektif ulama dan manfaat wakaf tunai sesuai maqashid syariah.

\section{B. METODE}

Penulisan artikel jurnal ini menggunakan metode studi pustaka yang di lakukan dengan cara mengumpulkan, menganalisis buku, karya ilmiah dan dokumen terkait seperti tesis dan jurnal yang berkaitan dengan wakaf tunai. Langkah-langkah yang di laksanakan dalam studi pustaka ini adalah mereduksi data dalam bentuk editing dan meringkas guna mendapat kan data utama mengenai intisari artikel, penyajian data, penarikan kesimpulan, verifikasi dan penelaahan terhadap data yang di peroleh agar dapat menarik hasil dengan benar (Sugiyono, 2011). 


\section{HASIL DAN PEMBAHASAN}

\section{Dasar Hukum Wakaf}

Dasar hukum wakaf ini berasal dari ayat Al-Quran dan Hadist yang menjadi patokan disyariatkan nya pelaksanaan wakaf, tetapi tidak langsung menjelaskan wakaf dalam alQur'an dan hadist, namun kata wakaf lebih sering disebut dengan kata infaq dan shodaqoh atau mengungkap kan dengan kata menginfaq kan sebagian harta di jalan Allah SWT. Namun dalam hadist lebih lebih di kenal dengan kata tahan atau "habs", sebagaimana seperti isi dari ayat Al-Qur'an dalam surat Ali-Imran: 92 sebagai berikut:

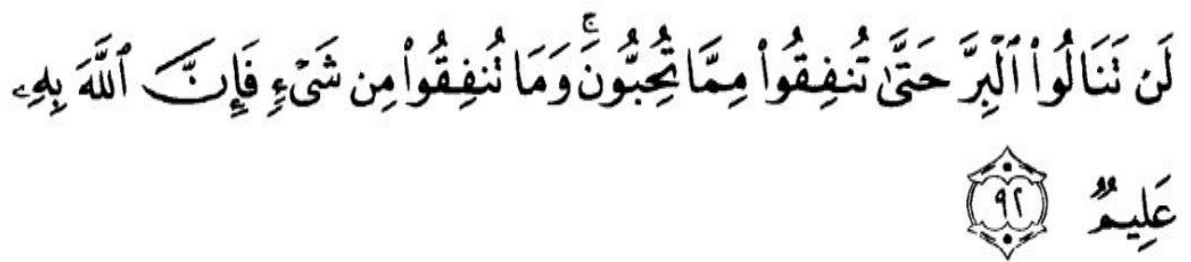

Artinya: "Kamu sekali-kali tidak sampai kepada kebajikan (yang sempurna) sebelum kamu menafkahkan sebagian harta yang kamu cintai. Dan apa saja yang kamu nafkahkan, maka sesungguhnya Allah mengetahui".

Selain itu, dalam Q.S Al-Hajj ayat 77 berbunyi:

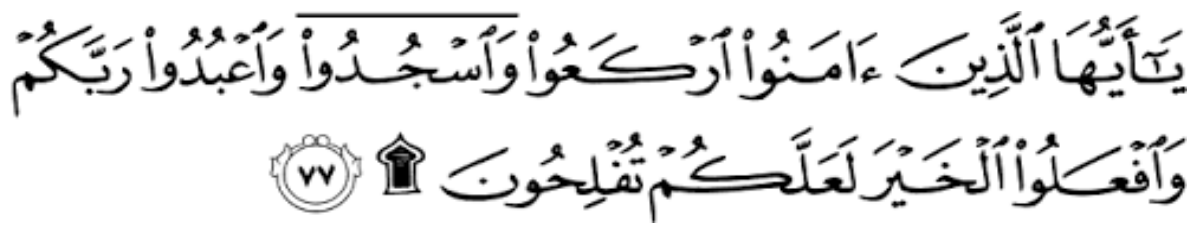

Artinya: "Hai orang-orang yang beriman, rukuklah kamu, sujudlah kamu dan sembahlah Tuhanmu, dan perbuatlah kebabaikan, supaya kamu mendapat kemenangan".

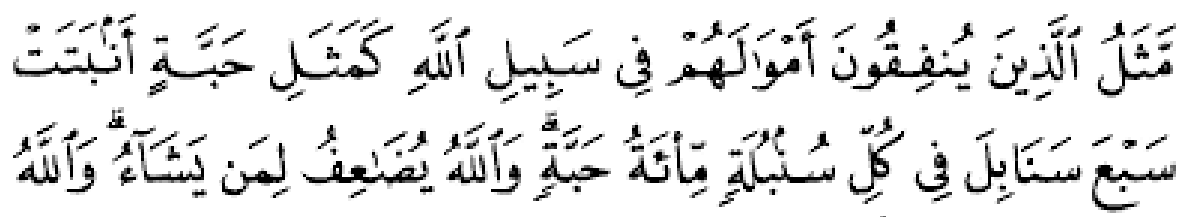

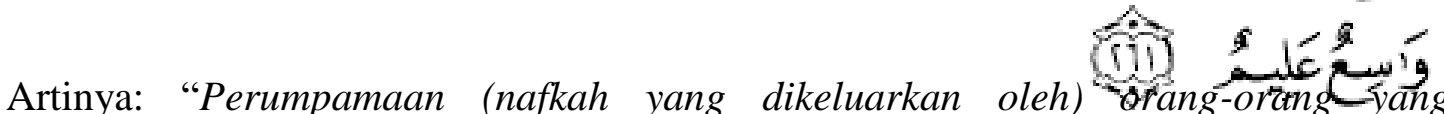
menafkahkan harta nya di jalan Allah, adalah serupa dengan sebutir benih yang menumbuhkan tujuh butir, pada tiap-tiap butir menumbuhkan seratus biji. Allah melipatgandakan (ganjaran) bagi siapa saja yang Dia kehendaki dan Allah Maha Luas (Karunia nya) lagi Maha Mengetahui." (QS. Al-Baqarah: 261).

Selain ayat-ayat Alquran di atas, ada juga hadits Nabi Muhammad SAW, lebih jelas nya ketika menceritakan anjuran ibadah wakaf yaitu perintah Nabi untuk memberikan Umar tanah nya di Khaibar.: 


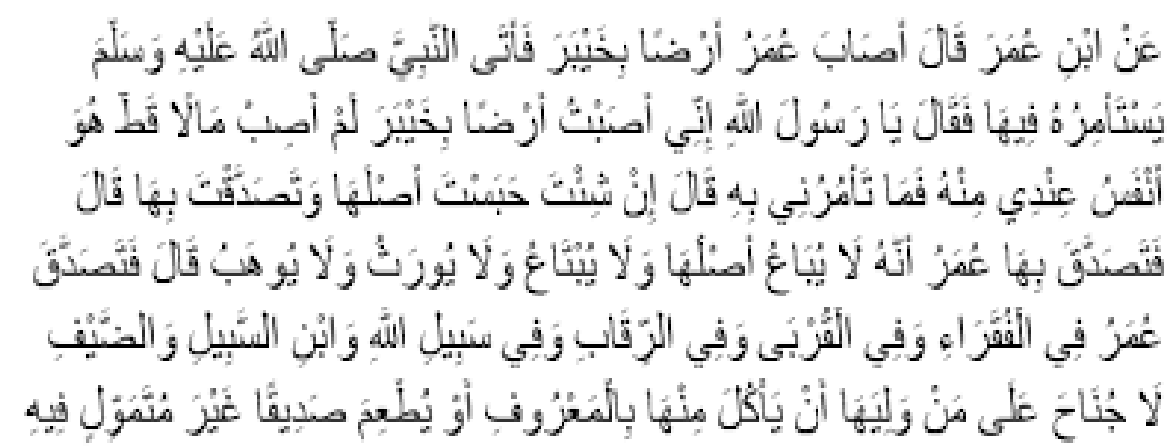

Artinya: "Dari Ibnu Umar r.a., bahwa Umar pernah mendapatkan sebidang tanah dari tanah Khaibar, lalu ia bertanya: 'Ya Rasulullah SAW, aku mendapatkan sebidang tanah di Khaibar, suatu harta yang belum pernah kudapatkan sama sekali yang lebih baik bagiku selain tanah itu, lalu apa yang hendak engkau perintahkan kepadaku? Maka jawab Rasulullah SAW; jika engkau suka tahanlah pokok nya dan sedekahkan hasil nya. Lalu umar menyedekahkan nya, dengan syarat tidak boleh dijual, tidak boleh diberikan dan tidak boleh diwariskan, yaitu orang-orang fakir, untuk keluarga dekat, untuk memerdekakan hamba sahaya, untuk menjamu tamu, dan untuk orang yang kehabisan bekal dalam perjalanan (ibnu sabil), dan tidak berdosa orang yang mengurusi nya itu untuk memakan sebagian nya dengan cara yang wajar dan untuk memberi makan (kepada keluarga nya) dengan syarat jangan dijadikan hak milik. Dan dalam suatu riwayat dikatakan; dengan syarat jangan dikuasai pokok nya" (H. R. Muslim).

Dari hadist tersebut dapat di ambil kesimpulan bahwa nadzir (pengurus wakaf) dapat mengambil sebagian dari hasil wakaf secara ma'ruf (patut). Dalam hadist lain juga disebutkan:

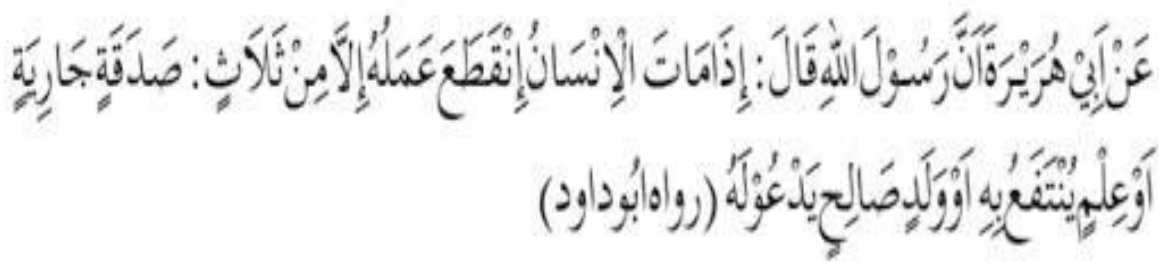

Artinya: Dari Abu Hurairah radhiyallahu anhu, "sesungguhnya Rasulullah SAW bersabda: "Apabila anak Adam (manusia) meninggal dunia, maka putuslah amal nya, kecuali tiga perkara: 1. shodaqah jariyah, 2. ilmu yang bermanfaat, 3. anak saleh yang mendoakan kedua orang tua nya" (H.R. Muslim No. 1631).

Memang tidak banyak ayat Al-Qur'an dan Hadist yang menyinggung tentang wakaf. Sebab itulah sedikit pula hukum-hukum wakaf yang ditetapkan berdasarkan kedua sumber tersebut. Meskipun demikian, ayat Al-Qur'an dan Hadist yang sedikit itu mampu menjadi pedoman para ahli fiqh Islam. 


\section{Definisi Wakaf Tunai}

Wakaf tunai adalah sedekah yang benda nya merupakan uang, yaitu dana atau uang yang di kumpulkan oleh lembaga pengelola wakaf (nadzir) melalui penerbitan sertifikat uang yang di beli oleh seseorang atau lembaga (Muhammad \& Prastiwi, 2015). Selain itu, cash waqf juga dapat dimaknai sebagai aset, dalam hal ini uang yang di sumbangkan oleh lembaga syariah seperti bank syariah atau lembaga ziswaf akan mengaturnya, yang keuntungan nya akan di sumbangkan kepada penerima wakaf, tetapi modalnya tidak dapat untuk di sedekahkan, sedangkan dan wakaf yang sudah di himpun selanjutnya dapat di distribusi kan dan di investasikan di berbagai bidang usaha halal dan produktif oleh Nadzir, kemudian di gunakan untuk pembangunan masyarakat sehingga akan menguntungkan dan bangsa secara global (Haq, 2013).

Makna wakaf tunai yang lainnya, ialah sedekah yang dilaksanakan oleh individu, perkumpulan orang, maupun institusi yang sudah memiliki badan hukum dalam melaksanakan cash waqf (Ula, 2016). Sementara Fatwa Majelis Ulama Indonesia (MUI) dalam (Muhammad \& Emy Prastiwi, 2015) mengemukakan cash waqf yaitu :

a. Cash Waqf ialah kegiatan yang di lakukan seorang individu, sekelompok masyarakat orang ataupun institusi berbadan hukum yang melaksankan cash waqf.

b. Cash wakaf juga bisa berarti sertifikat-sertifikat yang memiliki nilai ekonomis yang tinggi.

c. Cash waqf menurut MUI hukumnya boleh.

d. Di salurkan kepada seuatu yang bersifat halal saja

Kemudian nilai benda awaln harus dijaga kemurniannya, tidak untuk dijual, disedekahkan, dan atau pun diberikan sebagai waris. Wakaf tunai itu sebenar nya merupakan pembahasan para ulama sebelum nya. Beberapa sivitas akademika pun memiliki perbedaan pendapat tentang hukum Wakaf tunai. Pertama, mayoritas ulama (Malikiyyah, Syafi'iyyah, Hanabilah, dan sebagian Hanafiyah) berpendapat bahwa Wakaf tunai tidak sah karena dalam bentuk bendanya harus padat/utuh (tidak habis saat di gunakan) karena tidak memenuhi persyaratan wakaf. Kedua, beberapa mazhab Safi'iyah, Hanafi dan Imam Az Zuhri (meninggal 124H) mengizinkan Wakaf tunai dengan mengubah uang menjadi modal komersial yang hasinya di berikan kepada penerima wakaf. Ketiga, Imam Abu Hanifah membolehkan jika di guna kan dalam pembangunan masjid namun tidak di perboleh kan untuk memperbaiki jalan, mengairi dan bangunan lainnya.

Ibn Abidin berpendapat bahwa cash waqf, yang konon merupakan tradisi umum, merupakan tradisi umum dalam masyarakat Romawi, dan cash waqf bukanlah kebiasaan di 
negara lain. Oleh karena itu, Ibn Abidin ber pendapat bahwa cash waqf itu ilegal atau dilarang. Beliau juga berpendapat bahwa wakaf tunai seharus nya tidak boleh menurut mazhab Syafi'i. Begitupun Al Bakri, menurut mazhab Syafi'i tidak mengizinkan wakaf tunai karena dinar dan dirham (uang) akan hilang ketika di bayar kan, sehingga tidak ada lagi wujudnya.

Mohammad Musthafa Syalabi menjelaskan bahwa ada empat syarat untuk tujuan wakaf: pertama, properti harus mutaqawwim (memungkinkan untuk dilindungi dan di gunakan dengan cara tertentu); kedua, jika aset yang di sumbangkan dijaminkan oleh wakaf, maka dapat diketahui secara sempurna oleh wakaf dan pengelola wakaf (pembeli); Ketiga, benda yang di wakafkan secara sempurna berada pada milik wakif dan dapat di pindah kan apabila benda tersebut diikrarkan untuk wakaf, dan ke empat, benda yang merupakan milik wakif dapat dipisahkan secara mutlak tanpa terikat pada yang lain.

Di Indonesia terdapat peraturan perundang-undangan khusus mengenai wakaf yaitu dalam Undang-Undang No. 41 tentang wakaf tahun 2004 disebutkan bahwa wakaf ada dua jenis yaitu wakaf untuk harta bergerak dan wakaf untuk harta tidak gerak, wakaf bergerak ini termasuk wakaf tunai. (uang), logam mulia, surat berharga dan benda bergerak lain nya sesuai dengan ketentuan syariah dan hukum yang berlaku.

\section{Maqashid Syariah}

Ialah yang berarti tujuan dasar,harapan atau maksud akhir. Sementara lafal syariah adalah jembatan untuk mengarah kepada asal mata air dalam kehidupan. Menurut Al-Syatibi dalam (Febriadi, 2017), mengungkapkan bawah maqashid syariah memiliki kaidah kegunaan dalam segala ketetapan aspek hukum. Artinya, jika ada masalah, bisa dianalisis melalui maqashid syariah, yang bisa dilihat dari ruh syariah dan tujuan umum Islam. Teori maqashid syariah secara umum di rujuk dengan masalah ta'lil (penentuan hukum berasal dari illat) dan masalah al-mahalih dan mafasid (kegunaan dan kebangkrutan).

Seorang ahli hukum harus mengetahui tujuan dari Allah SWT dalam setiap syari'at nya (perintah atau larangan) agar fatwa nya sejalan dengan maksud Allah SWT sehingga, misal nya sesuatu yang merupakan kebutuhan manusia tetapi dihukum dengan sunnah atau mubah. Manfaat Maqasid Syariah adalah sebagai berikut:

a. Memahami teks dan hukum Alquran dan hadits secara komprehensif.

b. Menilai salah satu pendapat hukum berdasarkan Maqasid syariah sebagai salah satu standar (murajjihat). 
c. Ma'alat (pertimbangan jangka panjang), memahami aktivitas dan kebijakan manusia dan menghubungkan nya dengan ketentuan hukum nya (Oni, 2015).

Berdasarkan fakta di lapangan yang dikemukakan penulis, wakaf mempunyai nilai manfaat yang luar biasa jika dikelola secara maksimal oleh lembaga wakaf yang profesional. Hal tersebut juga telah di bukti kan oleh berbagai lembaga wakaf di Indonesia, seperti Pro 99 Wakaf dan R umah Wakaf Indonesia (RWI) di Bandung, Tabung Wakaf Indonesia Dompet Dhuafa (TWI), Wakaf al-Azhar dan Jakarta khusus nya atau dunia pada umum nya. Mesir, Irak, Turki dan lain-lain sama produktifnya dengan wakaf-wakaf pergerakan berbagai negara.

Oleh karena itu, pelaksanaan wakaf yang efisien tanpa meng abaikan prinsip syariah merupakan upaya yang sang at baik dan sesuai dengan ruh syariat Islam. Inilah yang dimaksud Ibn Qoyim al-Jauziyyah (Ibn Qoyim), yang menyatakan bahwa Ibn-i Qayyim alJauziyyah didirikan atas asas hikmah hukum Islam dan kemaslahatan manusia di dunia dan akhirat. Penalaran yang di gunakan untuk menghukum perbuatan tersebut adalah kasus hukum mașlahi, yaitu alasan untuk mengevaluasi baik buruk nya yang dapat terjadi ketika suatu kebijakan hukum diterapkan. Ahmed al-Raysuni menjel askan dalam sebuah buku bahwa ijtihad maṣlaḥ̄ dianggap benar jika memenuhi beberapa syarat dan kriteria. Yang pertama harus didasarkan pada tujuan utama dari kasus hukum maṣlaḥī (Ahmad al-Rasyuni, 2010).

Kedua, ijtihad maṣlaḥī harus di dasarkan pada ilmu maṣlaḥah al-syar'iyyah (kepentingan agama) dari semua jenis dan tingkatan (Ahmad al-Rasyuni, 2010). Ahmad alRaysîni membagi maslahah untuk keuntungan duniawi dan keuntungan bersifat ukhrawi. Ada juga manfaat seperti issi (terlihat dan terlihat) dan ma'nawī (abstrak). Selain itu, membagi nya menjadi kepentingan pribadi dan sosial serta kepentingan langsung atau tidak langsung dan lain-lain. Dia juga membagi tingkat ke tertarikan menjadi darūri (primer), hajji (sekunder) dan taḥsīni (tersier). Selain itu, apakah murni atau melengkapi, fardhu maslahat, sunah ataukah boleh saja. Berdasarkan hal tersebut, dapat di ambil kesimpulan bahwa gagasan cash waqf mencakup manfaat duniawi, kasat mata, sosial dan langsung. Dalam hal level, cash waqf adalah kemaslahatan primer yang murni dan wajib.

Ketiga, ijtihad maslahi harus menerapkan dan memperhatikan kegunaan umum baik dalam memahami Al-quran maupun teks hadits, konsep ini di terapkan dalam program wakaf uang. Manfaat yang di raih melalui program ini jauh lebih besar di banding kan dengan wakaf sosial murni seperti wakaf harta tak gerak, sebagaimana dipahami sebagian besar masyarakat selama ini. Selain mengalami penurunan nilai pondasi tidak bergerak, juga akan ada jangka waktu karena benda yang di sumbang kan akan mengakibatkan kerusakan, terpaan bencana 
alam dan berbagai sebab lain nya. Sedangkan dengan pendekatan wakaf uang, manfaat wakaf jauh lebih besar, dan manfaat dapat mengalir terus menerus dengan tetap menjaga aset asli. Jadi, tidak ada satu pun penataan pondasi klasik yang terpengaruh oleh ide ini.

Keempat, kasus hukum harus memperhitungkan perspektif biaya dan keuntungan. Ini menjadi ruh dan prinsip dari konsep wakaf produktif dengan uang. Bahkan yang jelas, konsep ini seolah menjadikan wakaf sebagai kawasan bisnis yang sangat menjanji kan yang manfaat nya dapat di nikmati semua pihak, tidak hanya bagi masyarakat pada umum nya, tetapi juga bagi instansi pemerintahan, pengawas wakaf, dan wakaf itu sendiri. Namun untuk menjaga kemurnian aset wakaf, nadzir harus terampil dan profesional, dalam artian program ini tidak bisa di katakan sebagai usaha murni, jika di rusak maka lembaga tersebut berakhir. Badan Wakaf Indonesia (BWI) telah menetapkan aturan yang sangat ketat mengenai kemungkinan hilangnya pekerjaan wakaf, yaitu setiap pengawas wajib memberikan kompensasi atas segala kerusakan yang terjadi pada bisnis wakaf. Dengan demikian, perlindungan aset wakaf dapat di laksanakan dan di kelola dengan baik (Muzarie, 2010).

Berdasarkan pandangan di atas maka dapat disimpulkan bahwa gagasan wakaf uang adalah suatu perbuatan yang sesuai dengan syariat Islam yang menginginkan kemaslahatan hidup manusia di dunia dan akhirat. Hal ini di perkuat pula dengan dalil bahwa ajaran Islam bersifat luwes dalam arti asas-asas dasar wakaf yang disepakati bersama, yaitu pelestarian harta kekayaan asli dan pembagian keuntungan kepada semua yang membutuhkan.

\section{KESIMPULAN}

Terdapat perbedaan pendapat mengenai hukum wakaf tunai oleh beberapa ulama. Yaitu pertama dari mayoritas ulama (Malikiyyah, Syafi'iyyah, Hanabilah dan sebagaian Hanafiyah) mengemukakan bahwa wakaf uang tidak sah, karena tidak memenuhi syaratsyarat wakaf, berupa bendanya utuh (tidak rusak ketika di manfaatkan). Kedua, sebagian mazhab syafi'iyyah, sebagian mazhab Hanafiyah dan Imam Az Zuhri (wafat tahun $124 \mathrm{H}$ ) membolehkan wakaf uang, dengan cara menjadikan uang tersebut sebagai modal usaha yang keuntungannya dialurkan kepada penerima wakaf. Ketiga, Imam Abu Hanifah merinci hukum wakaf uang, yaitu boleh jika digunakan untuk membangun masjid namun tidak membolehkan untuk bangunan diluar masjid seperti perbaikan jalan maupun membangun irigasi dan lain sebagainya.

Pendapat ulama mengenai obyek wakaf memperlihatkan bahwa syarat-syarat benda wakaf (harus benda, bermanfaat, tidak sekali pakai, tidak haram zatnya dan harus milik wakif secara sempurna). Wakaf tunai tidak didukung oleh hadist secara khusus, dan menggunakan 
ayat-ayat al-Qure an dan hadis bersifat umum. Oleh karena itu, penentuan syarat-syarat obyek wakaf termasuk wilayah ijtihadi. Maqasid syariah mengenai wakaf dengan tunai adalah sebuah gerakan atau gagasan cash waqf mengandung kemaslahatan yang bersifat duniawi, bisa dilihat, komunal, dan mendesak (segera). Dipandang dari segi tingkatannya, cash waqf adalah kemaslahatan ḍaūri (primer), murni dan wajib yang sesuai dengan syariat Islam yang menginginkan kemaslahatan hidup manusia di dunia dan akhirat.

\section{DAFTAR PUSTAKA}

Al Bakri. (tt). I"anatu Ath thalibin. Kairo: Isa Halabi.

Al-Jauziyyah, I. Q. (tt). I'lām al-Muwaqqi'īn 'an Rabb al- 'Ālamīn, Juz II.

Al-Raysūn̄̄, A. (2010). al-Ijtihād al-Mashlahī, Mashrū'iyyatuhūwa Manhajuhu. Riyaḍ: alMamlakah al-'Arabiyyah al-Su'ūdiyyah.

Al Sayyid, S. (1983). Fiqh As Sunat. Beirut: Dar Al Fikr.

Arif, S. (2010). Redistribusi Keuangan Islam. Jurnal Ekonomi Islam La Riba, 4(2003), 85115.

Aziz, M. W. (2017). Wakaf Tunai dalam Perspektif Hukum Islam. International Journal Ihya' Ulum Al-Din, 19(1): 1-24.

Febriadi, S. R. (2017). Aplikasi Maqashid Syariah dalam Bidang Perbankan Syariah. Amwaluna: Jurnal Ekonomi Dan Keuangan Syariah, 1(2), 231-245.

Haq, F. (2013). Wakaf Kontemporer, dari Teori ke Aplikasi. Fakultas Syariah IAIN Sunan Ampel.

Isfandiar, A. A. (2008). Tinjauan Fiqh Muamalat dan Hukum Nasional tentang Wakaf di Indonesia. La_Riba, 2(1), 51-73.

Karim, A. (2020). Proyek Wakaf Tunai. www.tazkiaonline.com. Diakses pada 1 November 2020 .

Mahfudz, H. (2014). Wakaf Produktif. www.republika.co.id. Diakses pada 1 November 2020.

Muzarie, M. (2010). Hukum Perwakafan dan Implikasinya Terhadap Kesejahteraan Masyarakat. Jakarta: Kementrian Agama RI.

Muhammad, A. A. S. (2018). Risalatu fi Jawazi Waqfi An Naqud. Beirut: Dar Ibn-Hazm.

Muhammad, T., \& Emy Prastiwi, I. (2015). Wakaf Tunai Perspektif Syariah. Jurnal Ilmiah Ekonomi Islam, 01(01), 61-74.

Munir, A. S. (2015). Optimalisasi Pemberdayaan Wakaf Secara Produktif. Ummul Quro, 6(2), 94-109.

Oni, S., Adiwarman, A. K. (2015). Maqashid Bisnus dan Keuangan Islam Sintetis Fiqih Ekonomi. Jakarta: Rajawali Press.

Rasmi, P. (tt). Maksud wakaf. Majelis Agama Islam Negeri Johor. www.maij.gov.my.

Sugiyono. (2011). Metode Penelitian Kauantitatif Kualitatif dan R\&D. Bandung: Alfabeta. 
Suryani., \& Yunal, I. (2016). Wakaf Produktif (Cash Waqf) dalam Perspektif Hukum Islam dan Maqasid Al-Shari'ah. Jurnal Penelitian Sosial Keagamaan, 24(1), 17-36.

Syam, T. R. (2006). Wakaf Tunai sebagai Salah Satu Sistem Perekonomian Islam. Cakim PA Tangerang.

Ula, U. M. (2016). Analisis Efisiensi Lembaga Pengelola Wakaf Tunai di Indonesia. Jurnal Ilmiah Mahasiswa Fakultas Ekonomi dan Bisnis Universitas Brawijaya.

Yusuf, M. (2015). Pemberdayaan Wakaf Produktif untuk Pemberdayaan Ekonomi Umat. Semarang: Balai Wakaf Nusantara. 